\title{
Real Personal Uncertainty Induced by Means of Task-Related Feedback: Effects on Reactions to Voice and No-Voice Procedures
}

\author{
Marjolein Maas $\cdot$ Kees van den Bos
}

Published online: 2 June 2011

(C) The Author(s) 2011. This article is published with open access at Springerlink.com

\begin{abstract}
Building and extending on research on uncertainty management and voice and no-voice procedures, we examine how real personal uncertainty moderates the way in which people react to getting or being denied an opportunity to voice one's opinions about decisions to be made. Specifically, results of two experiments show that conditions in which participants receive task-related feedback that induces personal uncertainty (versus conditions that produce more personal certainty) lead to stronger effects of voice and especially no-voice procedures on participants' procedural fairness judgments (Experiments 1 and 2). Findings also reveal that in these conditions stronger effects of voice and particularly no-voice procedures can be found on participants' anger about the way they have been treated, especially when participants are predisposed to react in intense terms to affect-related events (Experiment 2). Implications for the literature on uncertainty management and the social psychology of voice and no-voice procedures are discussed.
\end{abstract}

Keywords Personal uncertainty $\cdot$ Voice $\cdot$ Procedural fairness $\cdot$ Task performance . Affect intensity

M. Maas · K. van den Bos $(\bowtie)$

Department of Social and Organizational Psychology, Utrecht University,

Heidelberglaan 1, 3584 CS Utrecht, The Netherlands

e-mail: k.vandenbos@uu.nl

M. Maas (ه)

Department of Primary and Community Care, Research Centre for Social Care, Radboud University

Nijmegen Medical Centre, P.O. Box 9101, Route 152, 6500 HB Nijmegen, The Netherlands

e-mail: M.Maas@elg.umcn.nl 
The norms and values of fairness and justice play a vital role in various social settings. It is not surprising, therefore, that the issue of fairness and justice has received a lot of attention from scholars from a variety of disciplines, such as philosophy, sociology, political sciences, economics, and psychology (see, e.g., Beauchamp, 2001; Cohen, 1986). Within social psychology and other disciplines, it is shown convincingly that the experience of fair and unfair events may strongly influence people's subsequent reactions (Brockner \& Wiesenfeld, 1996; Folger \& Cropanzano, 1998; Lind \& Tyler, 1988; Paternoster, Brame, Bachman, \& Sherman, 1997; Tyler, Boeckmann, Smith, \& Huo, 1997). These findings suggest that perceived fairness plays an important role in social behavior. It is, therefore, important to examine when fairness matters to people (Folger, 1984; Tyler, 1990). In the present article, we will focus on this question.

How fair and unfair events may influence people's subsequent reactions can be illustrated by research studies in which it is manipulated whether people are allowed or withheld an opportunity to voice their opinions about decisions to be made (see, e.g., Folger, 1977; Folger, Rosenfield, Grove, \& Corkran, 1979; Van den Bos, 1999; Van den Bos \& Spruijt, 2002; Van Prooijen, Van den Bos, \& Wilke, 2004). In general, these studies show that people judge situations in which they are allowed to voice their opinions to be fairer than situations in which they are not allowed an opportunity to voice their opinions. This effect is called "the voice effect" (Folger, 1977).

Research done within the contexts pertaining to human task behavior shows that voice effects especially occur if people are given or denied the opportunity to voice their opinions before decisions are actually made (Lind, Kanfer, \& Earley, 1990). Furthermore, findings have frequently shown "fair process effects." For instance, it has been found that people are less likely to protest when they have experienced fair as opposed to unfair procedures (e.g., Lind \& Tyler, 1988), or that people are less angry after experiencing fair procedures (such as voice procedures) as opposed to unfair procedures (such as no-voice procedures; see, e.g., Van den Bos, 2001a). Thus, there now is a substantial body of research showing that voice and experienced procedural fairness can have strong effects on people's beliefs, attitudes, feelings, and behaviors (for overviews, see, e.g., Brockner \& Wiesenfeld, 1996; Folger \& Cropanzano, 1998; Lind \& Tyler, 1988; Tyler, 1988; Tyler et al., 1997).

To understand the frequently replicated voice and fair process effects, several reviews of the literature have suggested that the underlying psychological mechanisms should be studied more carefully (see, e.g., Folger \& Cropanzano, 1998; Lind \& Tyler, 1988; Tyler \& Lind, 1992; Van den Bos, 1999; Van den Bos \& Lind, 2002). One way of doing this is to focus on why fairness matters to people, more specifically examining the conditions under which people show strong reactions to fair and unfair events (see, e.g., Tyler, 1990; Van den Bos, 2001a; Van den Bos \& Lind, 2002; Van den Bos \& Maas, in press). Van den Bos and Lind (2002, 2009) argue in their uncertainty management model that people especially like to be treated in fair manners when they are uncertain about themselves, and that individuals find unfair treatment particularly aversive when they are uncertain about themselves. In short, the model suggests that when people are uncertain about 
themselves they will react especially strongly to fair and unfair events (such as voice and no-voice procedures) (for more extensive reviews of the uncertainty management model, see, e.g., Lind \& Van den Bos, 2002; Van den Bos, 2009; Van den Bos \& Lind, 2002, 2009; see also Loseman, Miedema, Van den Bos, \& Vermunt, 2009; Yavuz \& Van den Bos, 2009).

\section{Personal Uncertainty}

Thus, the uncertainty management model proposes that personal uncertainty is an important moderator of voice and fair process effects, and that studying the effects of this moderator may help to further insights into processes leading to voice and other fairness effects (Van den Bos \& Lind, 2002, 2009). Furthermore, building on various social psychological theories (e.g., Festinger, 1954; Hogg \& Mullin, 1999; Lopes, 1987; Sorrentino \& Roney, 1986; Weary \& Jacobson, 1997; Weary, Jacobson, Edwards, \& Tobin, 2001), the uncertainty management model argues that people have a fundamental need to feel certain about the world they live in and about their place in the world, that personal uncertainty can be threatening, and that people generally feel the urge to find a way to deal with their uncertainties (for extensive reviews of the uncertainty management model, see Lind \& Van den Bos, 2002; Van den Bos, 2009; Van den Bos, Martin, \& Stapel, 2010; Van den Bos \& Lind, 2002, 2009).

There are different types of uncertainties that people can encounter (Van den Bos $\&$ Lind, 2002). One noteworthy type of uncertainty that people often face when forming social judgments is informational uncertainty, which involves having less information available than one ideally would like to have to form a social judgment in a confident manner (see, e.g., Kahneman, Slovic, \& Tversky, 1982; Phelps, 1970). In the current article, we will focus on another type of uncertainty that we believe is very important when studying why fairness matters to people (Van den Bos \& Lind, 2009): personal uncertainty.

There are different definitions of personal uncertainty in the literature (see, e.g., De Cremer \& Sedikides, 2005; Sedikides, De Cremer, Hart, \& Brebels, 2009). Personal uncertainty, as we conceive of it, involves the implicit and explicit feelings people experience as a result of being uncertain about themselves, comprising for example uncertainties about their self-image, personal attitudes, aspirations, beliefs, emotions, or self-knowledge. We define personal uncertainty as the subjective sense of doubt or instability in people's self-views, world-views, or the interrelation between the two (Van den Bos, 2001a, 2007, 2009; Van den Bos, Poortvliet, Maas, Miedema, \& Van den Ham, 2005). Furthermore, we assume that experiencing personal uncertainty is a hot-cognitive social psychological process (Abelson, 1963), involving a combination of both cognitive and affective reactions (Van den Bos, 2007). We also think that personal uncertainty more often than not involves visceral and intuitive (instead of more reasoned and rationalistic) reactions (Maas \& Van den Bos, 2009). Experiencing personal uncertainty about one's attitudes, beliefs, feelings, and perceptions, as well as about one's relationship to other people, is generally aversive (e.g., Hogg, 2007), and personal uncertainty therefore often 
motivates behavior that seeks to reduce it. Although experiencing personal uncertainty may sometimes be sought out (e.g., Sorrentino, Bobocel, Gitta, Olson, \& Hewitt, 1988) and occasionally may instigate contemplation or introspection (e.g., Weary \& Jacobson, 1997), we argue that it is more common for people to find experiencing personal uncertainty an alarming or aversive event that does not allow for contemplation and introspection, but requires people to respond rather quickly to what is going on (Van den Bos et al., 2008).

In the literature on personal uncertainty, it is often argued that people have a drive to reduce their personal uncertainties (e.g., Berger \& Calabrese, 1975). The way in which people deal with or manage their personal uncertainties may differ. For example, work by McGregor, Zanna, Holmes, and Spencer (2001) shows that people manage their personal uncertainties by compensatory conviction about unrelated attitudes and values. Work by Van den Bos, Euwema, Poortvliet, and Maas (2007) reveals that personal uncertainty is an important determinant of how people react to socially deviating persons. The findings show that thinking about personal uncertainty as well as higher scores on a dimension measuring the extent to which uncertainty is considered to be an emotional threatening experience, lead people to mentally and physically distance themselves more from socially deviating people.

Related to this, Van den Bos (2001a) showed that when people have been thinking about their personal uncertainties, they react more strongly when they are being treated in fair versus unfair manners than when they have not been thinking about their personal uncertainties. Thus, when people's personal uncertainties have been made salient to them, fairness seems to matter especially to people, and fair events are much appreciated and unfair events are much hated. The net result is that conditions in which people's personal uncertainties are salient tend to produce stronger voice effects, stronger fair process effects, and stronger other fairness and cultural worldview effects (see, e.g., Van den Bos, 2001a; Van den Bos et al., 2005; Yavuz \& Van den Bos, 2009).

\section{The Current Research}

Although thinking of situations in which a person felt uncertain about him or herself may make personal uncertainty more accessible (Van den Bos, 2001a; Van den Bos et al., 2005; Yavuz \& Van den Bos, 2009), these studies (or any other published study known to us) do not reveal direct evidence that actually experienced uncertainty moderates peoples' fairness reactions. Therefore, we would like to extend the current research on uncertainty effects in the current paper and take it a step further. We would like to do this by focusing on how people react to voice and no-voice procedures when they have been confronted with real instances of personal uncertainty, as opposed to merely making personal uncertainty more accessible (cf. Van den Bos, 2001a; Van den Bos et al., 2005; Yavuz \& Van den Bos, 2009) or studying informational uncertainty as a moderator of justice judgments (cf. See, 2009; Thau, Bennett, Mitchell, \& Marrs, 2009). 
As we know from the social justice literature, voice and procedural fairness are important in task-related settings (e.g., Lind et al., 1990). Furthermore, receiving negative feedback about one's task performance may lead people to become uncertain about their performance capabilities, which may cause job-related uncertainty (Van den Bos, Heuven, Burger, \& Fernández Van Veldhuizen, 2006). We argue, therefore, that university students as research participants will feel uncertain about themselves when they cannot live up to their own expectations about performing well on simple tasks while they see others are able to complete quite easily. Thus, building on the uncertainty management hypothesis studied here, we propose that these research participants will react stronger to variations in procedure (voice vs. no voice), compared to participants who performed well on the tasks and hence would not feel uncertain about themselves.

In order to test this hypothesis, we present two experiments. In these experiments, we attempted to induce feelings of personal uncertainty by means of task-related feedback. We did this in the context of task-relevant behavior, in which receiving voice is important (Lind et al., 1990). As mentioned before, selfknowledge about one's own capabilities and knowing that one is correct are important to people (Festinger, 1954; Sorrentino, Brouwers, Hanna, \& Roney, 1996; Sorrentino \& Roney, 1986, 2000; Swann, 1990). Furthermore, people like to perform well on tests, like for example brain teasers and problem-solving tasks, and certainly when they perceive them to be a good measure of their ability and the tests are not too difficult. Getting feedback then that one in fact did poorly on an important and doable task creates confusion about one's ability and anxiety over failure. In short, negative performance feedback may cause feelings of personal uncertainty (e.g., Sorrentino et al., 1996; Sorrentino \& Roney, 2000). Therefore, in both experiments reported we will induce feelings of personal uncertainty by means of task performance feedback.

\section{Experiment 1}

In both the experiments to be presented in this article, feelings of personal uncertainty are induced before procedural justice was manipulated. To operationalize our manipulation of personal uncertainty, we will take advantage of the fact that our participants all are university students who generally hold the opinion that they should be able to perform well on relative simple tasks that have a diagnostic character regarding their intelligence. Being told that they have no aptitude for the tasks, or knowing that other people outperform them may cause them to doubt their own abilities causing feelings of personal uncertainty (see, e.g., Festinger, 1954; Sorrentino et al., 1996; Sorrentino \& Roney, 2000; Swann, 1990). To check that being in such a situation the task-related feedback they receive indeed will cause them to feel uncertain, our manipulation checks will ask participants whether they feel uncertain in this situation. ${ }^{1}$ The procedure manipulation consisted of a widely

\footnotetext{
${ }^{1}$ In both Experiments 1 and 2, we also measured social and performance state self-esteem (Heatherton \& Polivy, 1991; $\alpha \mathrm{s}>0.89$ ) in order to make sure that our manipulation of personal uncertainty indeed
} 
accepted and often examined manipulation of procedure: participants either did or did not receive an opportunity to voice their opinion about a decision that had to be made in the experiment (see, e.g., Brockner et al., 1998; Folger, 1977; Van den Bos, 1999; Weiss, Suckow, \& Cropanzano, 1999).

\section{Method}

\section{Participants and Design}

One hundred and forty-five students (39 men and 106 women) at Utrecht University participated in the experiment, and were paid $€ 4$ for their participation. Participants were randomly assigned to one of the conditions of the 2 (personal uncertainty: uncertain vs. certain) $\times 2$ (procedure: voice vs. no voice) factorial design.

\section{Experimental Procedure}

Participants were invited to the laboratory to participate in a study on how people perform computer tasks. On arrival at the laboratory, participants were led to separate cubicles, each of which contained a computer, monitor, and keyboard. Participants were informed that all computers were connected to one another and that communication with them could take place by means of the computer network. All further instructions were presented on the computer screens. The computers were used to present the stimulus information and to collect data on the dependent variables and manipulation checks.

Participants were informed that they were about to do a 10-min computer task in which their reaction times to given problems would be measured. Participants were also told that others generally experienced the computer task as a simple task. They were further informed that the purpose of the study was to investigate the quickness and accuracy with which people are able to solve the problems in this task. Then, participants read detailed instructions of the task. It was explained to the participants to keep their hands above the keyboard throughout the task, such that their left and right index fingers were above the " $x$ " and "." keys, respectively, and their left and right middle fingers were above the "z" and "/" keys, respectively. During the task, four blank circles appeared in a quadrangle on participants' computer screens. After $1 \mathrm{~s}$, randomly one of the circles turned black for $2 \mathrm{~s}$. Participants were asked to indicate as quickly as possible which circle turned black by pressing the corresponding key on the keyboard such that, if one of the two inner circles turned black they had to respond with the corresponding index finger. If one of the two outer circles turned black, they had to respond with their opposite middle finger (i.e., if the left outer circle turned black they had to respond with their right middle finger and vice versa). After

Footnote 1 continued

induced feelings of uncertainty and not simply lowered self-esteem. Findings obtained in both experiments did not show significant main effects nor interaction effects on these widely used and reliable state self-esteem scales. We did find, as reported in the "Results" sections, that participants reported more feelings of personal uncertainty in the uncertain compared to the certain conditions. Therefore, we conclude that in both Experiments 1 and 2 feelings of personal uncertainty were induced as intended. 
participants had pressed a key or when they did not press a key for $2 \mathrm{~s}$, the circles disappeared and a new set of four circles appeared on the screen.

After reading these instructions, participants were given the opportunity to practice the task. To ensure comprehension of the task, in the practice round the correct response was disclosed when participants pressed the wrong key. The practice round was followed by the 10-min work round. After completing the work round, participants were given a score that was supposedly based on how quickly they had responded and on the amount of mistakes they had made (actually all participants received a score of "17.36"). In the instructions, it was communicated to the participants that the lower their score would be, the better their performance. However, participants were not told how high or low their scores possibly could be. Thus, actually, participants did not know how well they scored on the task.

Receiving this ambiguous score was directly followed by the manipulation of personal uncertainty induced by task performance feedback. As mentioned, we were interested in the feelings of personal uncertainty evoked by participants' knowledge that they performed either poorly or good on a simple task. Therefore, in the condition in which we tried to make participants to feel uncertain about themselves and their task scores, participants read that their performance was very bad compared to the general norm, that they belonged to the $7 \%$ that performed worst on the task, and that $93 \%$ of the participants outperformed them on the task. In the condition in which we tried to make participants to feel certain about themselves, participants read that their performance was very good compared to the general norm, that they belonged to the $7 \%$ that performed best on the task, and that $93 \%$ of the participants performed worse on the task.

To ensure comprehension of this manipulation, participants were subsequently asked to indicate on dichotomous scales whether the task was in general experienced as a simple task or not, whether they belonged to the $7 \%$ that performed worst or best, whether $93 \%$ of the participants scored better or worse than they did, and whether their performance was very bad or very good compared to the general norm. All participants answered these questions correctly. Furthermore, to check whether feelings of personal uncertainty and certainty were induced by task performance feedback, participants were asked to what extent they agreed or disagreed with the following questions (all measured on 7-point Likert-type scales, $1=$ strongly disagree, 7 = strongly agree): "At this moment I am uncertain about my ability to perform well on this task"; "At this moment I doubt my ability to perform well on this task"; "At this moment I am uncertain about whether I am able to solve the given problems well"; "At this moment I doubt whether I am able to solve the given problems well"; "At this moment I am uncertain about whether I performed well on this task"; "At this moment I doubt whether I performed well on this task". All six questions were combined to form a reliable scale to check for feelings of task-related personal uncertainty $(\alpha=0.90)$.

After this, the procedure that participants received was manipulated. In the voice condition, participants were informed that the experimenter was interested in their opinions about a second task that would be the same as the first task and which they had to do at the end of the experiment. Therefore, they were asked to voice their opinions about whether they thought the second task was necessary and whether 
they would participate in the second task when given the opportunity. In the no-voice condition, participants were informed that the experimenter was not interested in their opinions about the second task and they were explicitly not given the opportunity to voice their opinions about whether they thought the second task was necessary and whether they would perform the second task when given the opportunity.

The procedure manipulation was followed by measuring procedural fairness judgments and the manipulation checks of procedure. All ratings were made on 7-point scales. Participants' procedural fairness judgments were assessed by asking them how fair $(1=$ very unfair, $7=$ very fair $)$, just $(1=$ very unjust, $7=$ very just $)$, appropriate $(1=$ very inappropriate, $7=$ very appropriate $)$, and justified $(1=$ very unjustified, $7=$ very justified $)$ they considered the way they were treated. These four items were averaged to form a reliable scale for procedural fairness judgments $(\alpha=0.92)$. To check whether the procedure manipulation was induced as intended, participants were asked to what extent they agreed with the following statement: "The experimenter was interested in my opinions" $(1=$ strongly disagree, 7 = strongly agree). This was followed by a careful debriefing in which participants were informed about the purposes of the study and the fictitious feedback they received during the experiment.

Results

\section{Manipulation Checks}

A $2 \times 2$ analysis of variance (ANOVA) on the scale that checked for feelings of taskrelated personal uncertainty yielded only a main effect of the uncertainty manipulation, $F(1,141)=9.56, P<0.01, \eta^{2}=0.06$. Participants in the uncertain condition experienced more feelings of uncertainty $(M=2.94, \mathrm{SD}=1.29)$ than participants in the certain condition $(M=2.35, \mathrm{SD}=0.98)$. This shows that our manipulation was successful in evoking feelings of task-related personal uncertainty.

A $2 \times 2$ ANOVA on the question that checked for the procedure manipulation yielded only a main effect of procedure, $F(1,141)=171.09, P<0.001, \eta^{2}=0.55$, indicating that participants in the voice condition agreed more strongly that the experimenter was interested in their opinions $(M=5.49, \mathrm{SD}=1.64)$ than participants in the no-voice condition $(M=1.95, \mathrm{SD}=1.63)$. Therefore, we can conclude that our procedure manipulation was successfully induced.

\section{Procedural Fairness Judgments}

A $2 \times 2$ ANOVA on the scale of participants' procedural fairness judgments yielded a significant main effect of procedure, $F(1,141)=97.26, P<0.001$, $\eta^{2}=0.41$, indicating that participants found voice procedures to be more fair $(M=5.25, \mathrm{SD}=0.90)$ than no-voice procedures $(M=3.77, \mathrm{SD}=0.92)$. This effect was qualified by the predicted interaction effect, $F(1,141)=6.07, P=0.01$, $\eta^{2}=0.04$. As expected, the effects of the procedure manipulation was stronger in the uncertain condition, $F(1,143)=61.39, P<0.001, \eta^{2}=0.30$, than in the 


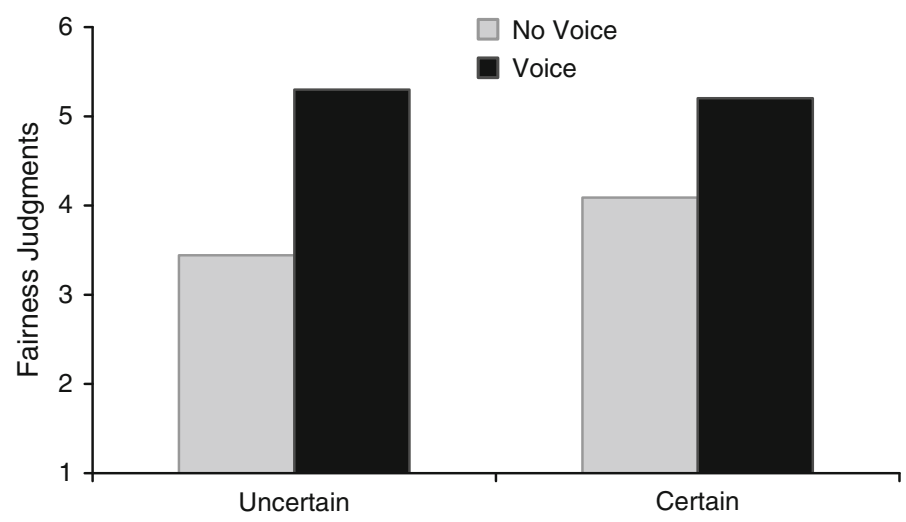

Fig. 1 Participants' procedural fairness judgments as a function of personal uncertainty and procedure (Experiment 1)

certain condition, $F(1,143)=18.52, P<0.001, \eta^{2}=0.11$. The results also indicated that participants in the no-voice condition found the procedures used less fair when they experienced uncertainty than when they experienced certainty, $F(1$, $143)=5.08, P=0.03, \eta^{2}=0.03$. There were no such effects in the voice condition (see Fig. 1).

\section{Discussion}

As predicted, participants reacted more strongly toward variations in voice procedures when they experienced task-induced personal uncertainty compared to participants who did not experience personal uncertainty. In other words, we replicated the voice effect (Folger, 1977) such that participants indicated that they thought the procedures were more fair when they had received an opportunity to voice their opinion than when they were denied that opportunity. Furthermore, the voice effect was especially strong in conditions in which personal uncertainty was induced by means of performance feedback. Specifically, participants in the condition in which they performed badly and hence felt relatively uncertain about themselves judged the no-voice procedure to be more unfair, compared to participants in the condition in which they performed well and thus did not experience personal uncertainty to a great extent. Thus, the findings of Experiment 1 provide supportive evidence for our line of reasoning that real personal uncertainty induced by task-related feedback influences fairness perceptions of voice and especially no-voice procedures. But before drawing strong conclusions on the basis of these results, it is important to replicate them in a second experiment.

\section{Experiment 2}

In Experiment 2, we tried to evoke feelings of uncertainty in an even more natural way than we did in Experiment 1. Specifically, in Experiment 2 personal uncertainty 
was induced by giving university students feedback that a comparable other person was much better (versus equally competent) in performing intelligent or brainteasing tasks. Furthermore, in Experiment 2 we assessed our manipulation check of induced personal uncertainty at the end of the experiment, instead of in-between the uncertainty and procedure manipulations as we did in Experiment 1. In this way, we ruled out the possibility that measuring feelings of task-related personal uncertainty in-between the manipulations might have interfered with our manipulations and their effects.

In addition to measuring procedural fairness judgments as our dependent variable, we also examined whether our predicted effects could be found on people's affective reactions to the way they had been treated in the experiment. Specifically, as we know from the fairness literature, giving or withholding people an opportunity to voice their opinions can result in fair process effects such that, for instance, people are less angry after experiencing fair procedures instead of unfair ones (Van den Bos, 2001a; see also Folger et al., 1979; Tyler \& Smith, 1998; Weiss et al., 1999). Thus, we will assess how angry our participants are about the way they have been treated.

Moreover, it has been suggested that predispositions in how people react to affect-related events (Larsen, Diener, \& Emmons, 1986) can moderate people's reactions to fair and unfair events (Van den Bos, Maas, Waldring, \& Semin, 2003). Thus, voice and fair process effects are supposed to be stronger for people who tend to react in strong affective terms to positive or negative events than for people who show mild or less intense affective reactions to events. Combining this insight with the hypotheses tested in Experiment 1, we will test in Experiment 2 the prediction that especially when people experience personal uncertainty, differences in affect intensity (Larsen et al., 1986) will moderate people's reactions to perceived fairness (Van den Bos et al., 2003; see also Maas \& Van den Bos, 2009).

\section{Method}

\section{Participants and Design}

One hundred twenty-three students (28 men and 95 women) at Utrecht University participated in the experiment, receiving course credits for their participation. Two weeks prior to the experiment participants filled out the affect intensity measure (AIM; Larsen et al., 1986). Examples of items from the AIM are "When I'm happy, I bubble over with energy" and "My negative moods are mild in intensity". All ratings were made on 7 -point Likert-type scales $(1=$ never, $7=$ always; $\alpha=0.82)$. At arrival at the laboratory, participants were randomly assigned to one of the two conditions of a 2 (personal uncertainty: uncertain vs. certain) $\times 2$ (procedure: voice vs. no voice) factorial design.

\section{Experimental Procedure}

Participants (one at a time) were seated on a chair at a table facing a female confederate (referred to as "Other"). The experimenter seated herself on a chair at 
the side of the table and read the instructions out loud. Participants were told that they would be asked to complete a test consisting of problem-solving tasks. They were further informed that this test constituted a validated measure of flexibility of the mind and intelligence. Participants were asked to solve as many problems during the completion of the problem-solving tasks as quickly and accurately as possible. The importance of the tasks was stressed by telling participants that the tasks measured important characteristics for academic success. The better participants would score on the test, the more of these important characteristics they supposedly would possess. It was further emphasized that the tasks in general were considered to be simple and doable. Participants and Other were then informed that they would both perform tasks in three rounds: two 90 s practice rounds that were followed by a 6-min main working round. Within all rounds participants were given different kinds of brain-teasing problems to solve. After checking that the participants understood the instructions, the first practice round started.

After this round, personal uncertainty was manipulated by means of taskrelated feedback. This was done both in the second practice round and in the main working round. In the uncertain condition, Other worked faster in the second practice round, solving more problems in the given $90 \mathrm{~s}$. Then, in the main working round participants and Other were given an amount of brain teasers that could not be solved in the given time and Other solved the given problems more quickly than the participant did. In the certain condition, Other worked equally fast in the second practice round, solving approximately an equal amount of problems in the given $90 \mathrm{~s}$. Then, in the main working round, participants and Other were given an amount of brain teasers that could be solved in the given time and Other worked equally fast as the participants throughout the entire task.

Next, participants and Other were informed they had to do another task in separate rooms and Other was taken to another room. Then, the experimenter asked the participants to take a seat behind the computer. The experimenter explained that the computer was connected to a network through which communication could take place. All further instructions were presented on the computer screen. The computers were used to present the procedure stimulus information and to collect data on the dependent variables and manipulation checks. After the experimenter left the room, the procedure manipulation was induced in the same way as in Experiment 1. The manipulation of procedure was followed by questions measuring participants' procedural fairness judgments, anger participants experienced as a result of the procedure, and the manipulation checks. All ratings were made on 7-point Likert-type scales. The same procedural fairness judgments were measured as in Experiment $1(\alpha=0.94)$. Similar to earlier studies (Van den Bos et al., 2005), the anger participants held toward the procedures used were assessed by asking participants to what extent they felt angry, furious, and enraged about the way they had been treated $(1=$ not at all, $7=$ completely $)$. These items were averaged to form a reliable anger index $(\alpha=0.92)$.

At the end of the experiment, we assessed our manipulation checks. To check whether participants felt uncertain or certain, they were asked the same six questions as in Experiment 1 plus the following two questions: "If you think about 
the way you have performed yourself on these tasks, to what extent do you become uncertain?" ( 1 = absolutely not, $7=$ completely $)$, and "If you think about the way Other has performed on these tasks, to what extent do you become uncertain?" ( 1 = absolutely not, 7 = completely). All eight uncertainty questions were combined to form a reliable scale of feelings of uncertainty $(\alpha=0.93)$. The manipulation of procedure was checked in the same way as in Experiment 1. This was followed by a careful debriefing about the purposes of the study and the feedback participants received during the experiment.

\section{Results}

In all analyses, we regressed the manipulation checks or dependent variables on AIM, personal uncertainty, and procedure, testing for all main effects and all interactions. Following Cohen, Cohen, West, and Aiken (2003), we centralized the continuous AIM variable and effect-coded the variables pertaining to the uncertainty and procedure manipulations.

\section{Manipulation Checks}

As expected, on the scale that checked for feelings of personal uncertainty we found a significant main effect of the uncertainty manipulation, $\beta=-0.23, t(115)=$ $-2.55, P=0.01$, indicating that participants in the uncertain condition experienced more feelings of uncertainty $(M=3.57, \mathrm{SD}=1.36)$ than participants in the certain condition $(M=3.00, \mathrm{SD}=1.11)$. Thus, similar to Experiment 1 , we found reliable effects of our uncertainty manipulation on participants' feelings of personal uncertainty, independently from the other manipulated variable (procedure). We further found that participants' feelings of uncertainty were related to participants' scores on the affect intensity measure. That is, we found a main effect of AIM, $\beta=0.21, t(115)=2.25, P=0.03$, indicating that when participants scored higher on the affect intensity measure, they reported to feel more uncertain. This result is not unexpected, since we know from the literature that affect intensity especially evokes divergent reactions for people high and low in affect intensity in response to situations containing affective stimuli (Larsen \& Diener, 1987; Van den Bos et al., 2003). In line with this observation, we also found an interaction effect between personal uncertainty and AIM, $\beta=0.21 t(115)=2.25, P=0.03$, indicating that in the uncertain condition participants reported more feelings of task-related personal uncertainty when their affect intensity scores were higher, $\beta=0.30, t(61)=2.49$, $P=0.02$, whereas there was no such effect in the certain condition, $\beta=0.06$, $t(58)=0.47, n s$.

As expected, the question that checked for the procedure manipulation showed a significant main effect of procedure, $\beta=0.68, t(115)=10.14, \quad P<0.001$, indicating that participants in the voice condition though that the experimenter was more interested in their opinions $(M=4.94, S D=1.42)$ than participants in the no-voice condition $(M=2.41, S D=1.07)$. This effect was not moderated by the other independent variables. 


\section{Procedural Fairness Judgments}

Participants' procedural fairness judgments yielded a significant main effect of procedure, $\beta=0.49, t(115)=6.93, P<0.001$, a significant main effect of AIM, $\beta=-0.35, t(115)=-4.72, P<0.001$, and a significant two-way interaction between AIM and procedure, $\beta=0.31, t(115)=4.24, P<0.001$. These effects were qualified by the predicted three-way interaction effect, $\beta=-0.15$, $t(115)=-2.09, P=0.04$. Figure 2 illustrates these effects.

To get a better insight into the three-way interaction effect, we conducted twoway regression analyses in both the uncertain and certain conditions. In the uncertain condition this yielded a significant main effect of procedure, $\beta=0.39$, $t(59)=3.72, P<0.001$, indicating that participants judged the procedure to be more fair when they received voice $(M=5.58, \mathrm{SD}=1.10)$ than when they did not receive voice $(M=4.55, \mathrm{SD}=1.27)$. Moreover, this effect was qualified by a significant two-way interaction effect, $\beta=0.42, t(59)=3.91, P<0.001$, indicating that especially when participants scored higher on AIM, not receiving an opportunity to voice their opinion was judged to be less fair, $\beta=-0.58, t(28)=$ $-3.80, P=0.001$. No significant simple effects were found for participants who did receive voice. The left part of Fig. 2 shows these effects.

In the certain condition, we found a significant main effect of AIM, $\beta=$ $-0.51, t(56)=-5.39, P<0.001$, and a significant main effect of procedure, $\beta=0.57, t(56)=6.08, \quad P<0.001$, and no interaction effect. Thus, when participants felt certain, they judged the procedures to be less fair as they scored higher on affect intensity. Furthermore, when participants received voice they judged the procedures to be more fair $(M=5.60, \mathrm{SD}=1.05)$ than when they did not receive voice $(M=3.54, S D=0.89)$. The right part of Fig. 2 shows these effects.

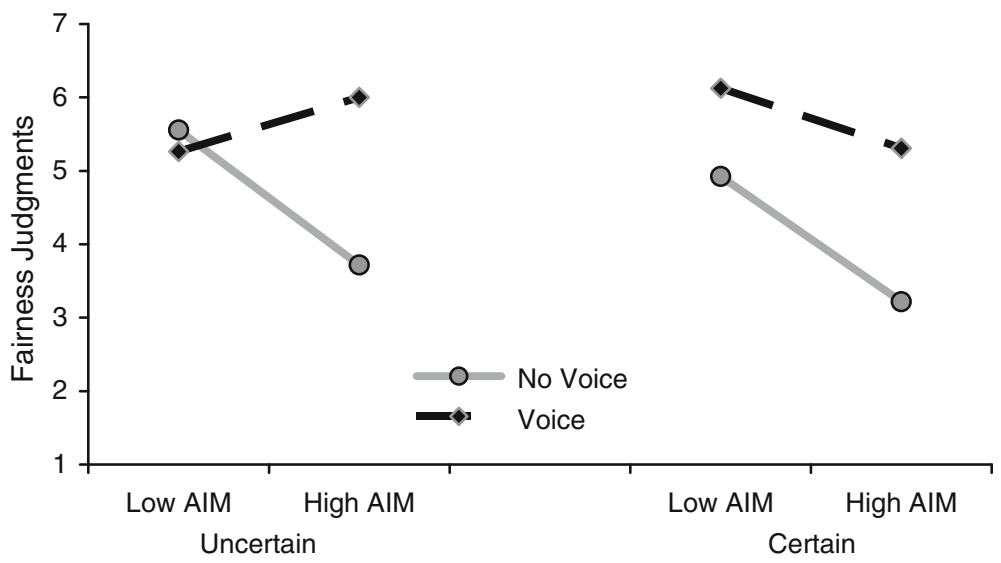

Fig. 2 Participants' procedural fairness judgments as a function of affect intensity (one SD above and below the mean), personal uncertainty, and procedure (Experiment 2) 


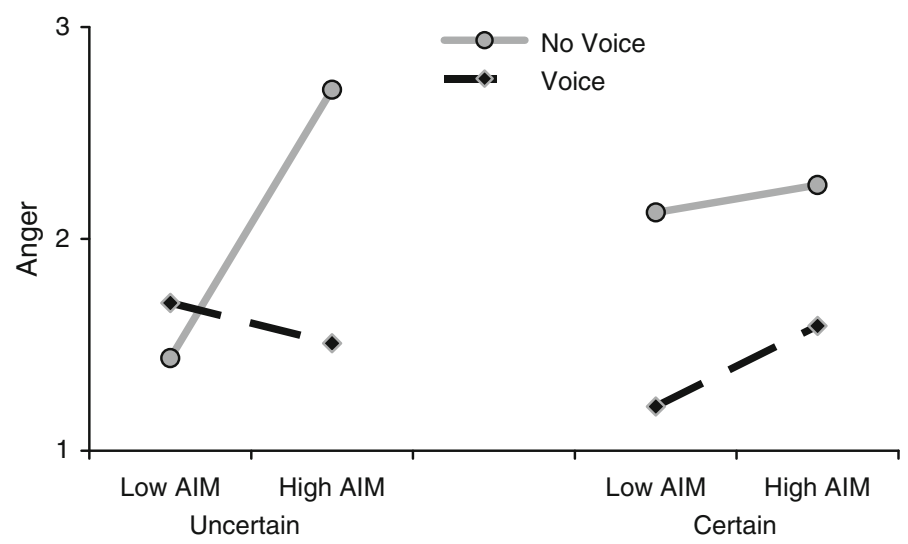

Fig. 3 Anger experienced toward the procedures used as a function of affect intensity (one SD above and below the mean), personal uncertainty, and procedure (Experiment 2)

Anger

On the scale that measured the amount of anger participants held toward the procedures used, we found a significant main effect of procedure, $\beta=-0.31$, $t(115)=-3.56, P<0.01$, and a significant main effect of AIM, $\beta=0.20$, $t(115)=2.17, P=0.03$. These effects were qualified by the predicted three-way interaction, $\beta=0.20, t(115)=2.27, P=0.03$. Figure 3 graphs these effects.

To get a better insight into the three-way interaction, we conducted two-way regression analyses in both the certain and uncertain conditions. In the uncertain condition, this yielded a significant interaction effect between procedure and personal uncertainty, $\beta=-0.29, t(59)=-2.43, P=0.02$, indicating that participants who felt uncertain experienced more anger after not receiving an opportunity to voice their opinion when they scored higher on affect intensity, $\beta=0.45$, $t(28)=2.68, P=0.01$. No effects were found for participants who received an opportunity to voice their opinion. The left part of Fig. 3 shows these effects. In the certain condition, we only found a significant main effect of procedure, $\beta=-0.38$, $t(56)=-3.05, P<0.01$. Thus, when participants were relatively certain about their task performance, they felt less anger when they had received voice $(M=1.45, \mathrm{SD}=0.76)$ than when they had not receive voice $(M=2.20$, $\mathrm{SD}=1.18$ ). The right part of Fig. 3 shows these effects.

\section{General Discussion}

Thus, as predicted, we found in Experiment 2 that especially in conditions in which task-related feedback caused participants to experience feelings of personal uncertainty (compared to feedback conditions in which this was not the case) that participants showed stronger reactions to voice and especially no-voice procedures, particularly when participants were predisposed to react intensely to affect-related 
events. This effect was found on both procedural fairness judgments and participants' anger against the way they had been treated.

Taken together, this article presents two studies that further develop the idea that personal uncertainty moderates the effects of voice and especially no-voice procedures on procedural fairness judgments and affective reactions, specifically anger reactions. One explicit contribution of the current article is to have revealed that task-related feedback may impact personal uncertainty and that different feedback conditions hence may moderate reactions to voice and particularly novoice procedures. In this way, the present studies extend beyond earlier studies that examined the moderating role of mere cognitive activation of the uncertainty construct (cf. Yavuz \& Van den Bos, 2009; Van den Bos, 2001a, 2001b; Van den Bos et al., 2005) or studied the role of informational uncertainty in the fairness judgment process (cf. See, 2009; Thau et al., 2009). Showing that real experiences of personal uncertainty can lead to predictable responses to procedural fairness issues lends credence to the uncertainty management model and past work in this area (see, e.g., Lind \& Van den Bos, 2002; Van den Bos, 2009; Van den Bos \& Lind, 2002, 2009).

One noteworthy finding obtained in both experiments is that "the voice effect" we found was such that when participants were being denied voice this led to more negative reactions, whereas the presence of voice did not necessarily led to more positive reactions. This is a pattern that has been reported before in the research literature (e.g., Van den Bos \& Spruijt, 2002; Van den Bos \& Van Prooijen, 2001), suggesting that no-voice conditions frequently lead to more negative reactions as opposed to voice conditions lead to more positive judgments (see also Brockner \& Wiesenfeld, 1996). This implies that what typically is labeled as the "voice effect" (suggesting more positive judgments following voice) might actually be thought of more properly as a "no-voice" effect (indicating more negative judgments following no voice).

By building upon procedural fairness research within task behavior contexts (Lind et al., 1990) and based on social psychological theories on uncertainty (e.g., Festinger, 1954; Hogg \& Mullin, 1999; Sorrentino \& Roney, 1986, 2000; Weary \& Jacobson, 1997; Weary et al., 2001), we have induced feelings of uncertainty by task performance feedback. In both experiments participants indicated that they felt more task-related personal uncertainty when they had been told that they did not perform well on the tasks in our experiments as opposed to when they did perform well. One might wonder whether our feedback manipulations would have had an effect on other important psychological concepts. One such concept is state self-esteem, but, as we report in footnote 1 , effects of both experiments did not reveal any effects on widely used and reliable scales of both social and performance state self-esteem (Heatherton \& Polivy, 1991). The effects we did find, however, revealed the predicted effects on questions measuring people's feelings of task-related personal uncertainty. Therefore, we would like to conclude for now that our findings provide evidence for our line of reasoning that our manipulations of giving feedback to participants that they were not (versus were) successful in performing important (i.e., intelligence-related) and doable tasks lowered their feelings of personal uncertainty. Future research is needed to examine the effects on other possible concepts. Future research may also want to 
use other possible operationalizations of real personal uncertainty and study how these operationalizations impact reactions to fair and unfair events. For now we can conclude that the task-related feedback that we gave our participants had predictable effects on ratings of personal uncertainty, procedural fairness judgments, and anger reactions, and not on state self-esteem.

We also should note here that there are important individual differences in how people cope with uncertainty and that this can impact their reactions considerably (see, e.g., Greco \& Roger, 2001; Sorrentino \& Roney, 2000). Furthermore, we know from the literature that some uncertainties can be pleasant and engaging (Sorrentino \& Roney, 2000). It would be interesting to sort out what differential effects various types of uncertainty might have on people's fairness reactions. This noted, for our line of reasoning, we attended to the more commonly experience following personal uncertainty, which are generally aversive reactions (Hogg \& Mullin, 1999; McGregor \& Marigold, 2003; Sorrentino \& Roney, 1986; Van den Bos \& Lind, 2002), and we showed that in task-relevant situations, personal uncertainty causes people to react more strongly to variations in voice and especially no-voice procedures. Future research could also study other operationalizations of voice and no-voice procedures (see, e.g., Van den Bos, 1999) and other fairness manipulations (see, e.g., Tyler \& Smith, 1998).

In conclusion, we think it is reasonably to note that the findings of the current research tell us something important about people's reactions to fair and unfair events, and especially voice and no-voice procedures. In the face of real time experienced personal uncertainty, which can be induced by means of task-related feedback, fairness seems to especially matters to people, and they react in particularly positive terms to voice procedures and in especially negative terms to no-voice procedures. This suggests that not only thinking about the uncertainties in life (cf. Van den Bos, 2001a), but actually being confronted with performance feedback that causes feelings of uncertainty, is an important determinant of fairness reactions. These findings may help in the progress of understanding why voice and no-voice procedures (being among the most important procedural fairness encounters people can experience) matter to people.

Acknowledgments The research reported in this article was supported by grants from the Netherlands Organization for Scientific Research awarded to Kees van den Bos (Van der Leeuw grant and VICI grant 453.03.603).

Open Access This article is distributed under the terms of the Creative Commons Attribution Noncommercial License which permits any noncommercial use, distribution, and reproduction in any medium, provided the original author(s) and source are credited.

\section{References}

Abelson, R. P. (1963). Computer simulation of "hot cognitions. In S. S. Tomkins \& S. Messick (Eds.), Computer simulation and personality: Frontier of psychological theory (pp. 277-298). New York: Wiley.

Beauchamp, T. L. (2001). Philosophical ethics: An introduction to moral philosophy. New York: McGraw-Hill. 
Berger, C. R., \& Calabrese, R. J. (1975). Some explorations in initial interaction and beyond: Toward a developmental theory of interpersonal communication. Human Communication Research, 1, $99-112$.

Brockner, J., Heuer, L., Siegel, P. A., Wiesenfeld, B., Martin, C., Grover, S., et al. (1998). The moderating effect of self-esteem in reaction to voice: Converging evidence from five studies. Journal of Personality and Social Psychology, 75, 394-407.

Brockner, J., \& Wiesenfeld, B. M. (1996). An integrative framework for explaining reactions to decisions: Interactive effects of outcomes and procedures. Psychological Bulletin, 120, 189-208.

Cohen, R. L. (1986). Justice: Views from the social sciences. New York: Plenum Press.

Cohen, J., Cohen, P., West, S. G., \& Aiken, L. S. (2003). Applied multiple regression/correlation analysis for the behavioral sciences (3rd ed.). Mahwah, NJ: Lawrence Erlbaum Associates, Publishers.

De Cremer, D., \& Sedikides, C. (2005). Self-uncertainty and responsiveness to procedural justice. Journal of Experimental Social Psychology, 41, 157-173.

Festinger, L. (1954). A theory of social comparison processes. Human Relations, 7, 117-140.

Folger, R. (1977). Distributive and procedural justice: Combined impact of "voice" and improvement of experienced inequity. Journal of Personality and Social Psychology, 35, 108-119.

Folger, R. (1984). Preface. In R. Folger (Ed.), The sense of injustice: Social psychological perspectives (pp. ix-x). New York, NY: Plenum Press.

Folger, R., \& Cropanzano, R. (1998). Organizational justice and human resource management. Thousand Oaks, CA, USA: Sage Publications.

Folger, R., Rosenfield, D., Grove, J., \& Corkran, L. (1979). Effects of "voice" and peer opinions on responses to inequity. Journal of Personality and Social Psychology, 37, 2253-2261.

Greco, V., \& Roger, D. (2001). Coping with uncertainty: The construction and validation of a new measure. Personality and Individual Differences, 31, 519-534.

Heatherton, T. F., \& Polivy, J. (1991). Development and validation of a scale for measuring state selfesteem. Journal of Personality and Social Psychology, 60, 895-910.

Hogg, M. A. (2007). Uncertainty-identity theory. In M. P. Zanna (Ed.), Advances in experimental social psychology (Vol. 39, pp. 70-126). San Diego, CA: Academic Press.

Hogg, M. A., \& Mullin, B. A. (1999). Joining groups to reduce uncertainty: Subjective uncertainty reduction and group identification. In D. Abrams \& M. A. Hogg (Eds.), Social identity and social cognition (pp. 249-279). Malden: Blackwell.

Kahneman, D., Slovic, P., \& Tversky, A. (Eds.). (1982). Judgment under uncertainty: Heuristics and biases. Cambridge: Cambridge University Press.

Larsen, R. J., \& Diener, E. (1987). Affect intensity as an individual difference characteristic: A review. Journal of Research in Personality, 21, 1-39.

Larsen, R. J., Diener, E., \& Emmons, R. A. (1986). Affect intensity and reactions to daily life events. Journal of Personality and Social Psychology, 51, 803-814.

Lind, E. A., Kanfer, R., \& Earley, P. C. (1990). Voice, control, and procedural justice: Instrumental and noninstrumental concerns in fairness judgments. Journal of Personality and Social Psychology, 59, 952-959.

Lind, E. A., \& Tyler, T. R. (1988). The social psychology of procedural justice. New York: Plenum Press.

Lind, E. A., \& Van den Bos, K. (2002). When fairness works: Toward a general theory of uncertainty management. In B. M. Staw \& R. M. Kramer (Eds.), Research in organizational behavior (Vol. 24, pp. 181-223). Oxford: Elsevier.

Lopes, L. L. (1987). Between hope and fear: The psychology of risk. Advances in Experimental Psychology, 20, 255-295.

Loseman, A., Miedema, J., Van den Bos, K., \& Vermunt, R. (2009). Exploring how people respond to conflicts between self-interest and fairness: The influence of threats to the self on affective reactions to advantageous inequity. Australian Journal of Psychology, 61, 13-21.

Maas, M., \& Van den Bos, K. (2009). An affective-experiential perspective on reactions to fair and unfair events: Individual differences in affect intensity moderated by experiential mindsets. Journal of Experimental Social Psychology, 45, 667-675.

McGregor, I., \& Marigold, D. C. (2003). Defensive zeal and the uncertain self: What makes you so sure? Journal of Personality and Social Psychology, 85, 838-852.

McGregor, I., Zanna, M. P., Holmes, J. G., \& Spencer, S. J. (2001). Compensatory conviction in the face of personal uncertainty: Going to extremes and being oneself. Journal of Personality and Social Psychology, 80, 472-488. 
Paternoster, R., Brame, R., Bachman, R., \& Sherman, L. W. (1997). Do fair procedures matter? The effect of procedural justice on spouse assault. Law and Society Review, 31, 163-204.

Phelps, E. S. (1970). Microeconomic foundations of employment and inflation theory. New York: Norton.

Sedikides, C., De Cremer, D., Hart, C. M., \& Brebels, L. (2009). Procedural fairness responses in the context of self-uncertainty. In R. M. Arkin, K. C. Oleson, \& P. J. Carroll (Eds.), Handbook of the uncertain self (pp. 142-159). New York: Psychology Press.

See, K. E. (2009). Reactions to decisions with uncertain consequences: Reliance on perceived fairness versus predicted outcomes depends on knowledge. Journal of Personality and Social Psychology, 96, 104-117.

Sorrentino, R. M., Bobocel, D. R., Gitta, M. Z., Olson, J. M., \& Hewitt, E. C. (1988). Uncertainty orientation and persuasion: Individual differences in the effects of personal relevance on social judgments. Journal of Personality and Social Psychology, 55, 357-371.

Sorrentino, R. M., Brouwers, M. C., Hanna, S. E., \& Roney, C. R. J. (1996). The nature of the test taking situation: Informational and affective influences on intelligence test performance. Learning and Individual Differences, 8, 105-120.

Sorrentino, R. M., \& Roney, C. J. R. (1986). Uncertainty orientation, achievement-related motivation and task diagnosticity as determinants of task performance. Social Cognition, 4, 420-436.

Sorrentino, R. M., \& Roney, C. J. R. (2000). The uncertain mind: Individual differences in facing the unknown. Philadelphia: Psychology Press.

Swann, W. B., Jr. (1990). To be adored or to be known? The interplay of self-enhancement and selfverification. In E. T. Higgins \& R. M. Sorrentino (Eds.), Handbook of motivation and cognition: Foundations of social behavior (Vol. 2, pp. 408-448). New York: Guilford Press.

Thau, S., Bennett, R. J., Mitchell, M. S., \& Marrs, M. B. (2009). How management style moderates the relationship between abusive supervision and workplace deviance: An uncertainty management theory perspective. Organizational Behavior and Human Decision Processes, 108, 79-92.

Tyler, T. R. (1988). What is procedural justice? Criteria used by citizens to assess the fairness of legal procedures. Law and Society Review, 22, 103-135.

Tyler, T. R. (1990). Why do people obey the law? Procedural justice, legitimacy, and compliance. New Haven, CT: Yale University Press.

Tyler, T. R., Boeckmann, R. J., Smith, H. J., \& Huo, Y. J. (1997). Social justice in a diverse society. Oxford: Westview Press.

Tyler, T. R., \& Lind, E. A. (1992). A relational model of authority in groups. In M. P. Zanna (Ed.), Advances in experimental social psychology (Vol. 25, pp. 115-191). San Diego, CA, USA: Academic Press.

Tyler, T. R., \& Smith, H. J. (1998). Social justice and social movements. In D. Gilbert, S. T. Fiske, \& G. Lindzey (Eds.), Handbook of Social Psychology (Vol. 4, pp. 595-629). Boston, MA: McGraw-Hill.

Van den Bos, K. (1999). What are we talking about when we talk about no-voice procedures? On the psychology of the fair outcome effect. Journal of Experimental Social Psychology, 35, 560-577.

Van den Bos, K. (2001a). Uncertainty management: The influence of uncertainty salience on reactions to perceived procedural fairness. Journal of Personality and Social Psychology, 80, 931-941.

Van den Bos, K. (2001b). Reactions to perceived fairness: The impact of mortality salience and selfesteem on ratings of negative affect. Social Justice Research, 14, 1-23.

Van den Bos, K. (2007). Hot cognition and social justice judgments: The combined influence of cognitive and affective factors on the justice judgment process. In D. de Cremer (Ed.), Advances in the psychology of justice and affect (pp. 59-82). Greenwich, CT: Information Age Publishing.

Van den Bos, K. (2009). Making sense of life: The existential self trying to deal with personal uncertainty. Psychological Inquiry, 20, 197-217.

Van den Bos, K., Euwema, M. C., Poortvliet, P. M., \& Maas, M. (2007). Uncertainty management and social issues: Uncertainty as important determinant of reactions to socially deviating people. Journal of Applied Social Psychology, 37, 1726-1756.

Van den Bos, K., Ham, J., Lind, E. A., Simonis, M., Van Essen, W. J., \& Rijpkema, M. (2008). Justice and the human alarm system: The impact of exclamation points and flashing lights on the justice judgment process. Journal of Experimental Social Psychology, 44, 201-219.

Van den Bos, K., Heuven, E., Burger, E., \& Fernández Van Veldhuizen, M. (2006). Uncertainty management after reorganizations: The ameliorative effect of outcome fairness on job uncertainty. International Review of Social Psychology, 19, 75-86. 
Van den Bos, K., \& Lind, E. A. (2002). Uncertainty management by means of fairness judgments. In M. P. Zanna (Ed.), Advances in experimental social psychology (Vol. 34, pp. 1-60). San Diego: Academic Press.

Van den Bos, K., \& Lind, E. A. (2009). The social psychology of fairness and the regulation of personal uncertainty. In R. M. Arkin, K. C. Oleson, \& P. J. Carroll (Eds.), Handbook of the uncertain self (pp. 122-141). New York: Psychology Press.

Van den Bos, K., \& Maas, M. (in press). Adhering to consistency principles in an unjust world: Implications for sense-making, victim blaming, and justice judgments. In B. Gawronski \& F. Strack (Eds.), Cognitive consistency: A fundamental principle in social cognition. New York: Guilford.

Van den Bos, K., Maas, M., Waldring, I. E., \& Semin, G. R. (2003). Toward understanding the psychology of reactions to perceived fairness: The role of affect intensity. Social Justice Research, 16, 151-168.

Van den Bos, K., Martin, L. L., \& Stapel, D. A. (2010). Meaning making in delayed-return cultures: The case of personal uncertainty. Social and Personality Psychology Compass, 4, 559-573.

Van den Bos, K., Poortvliet, P. M., Maas, M., Miedema, J., \& Van den Ham, E.-J. (2005). An enquiry concerning the principles of cultural norms and values: The impact of uncertainty and mortality salience on reactions to violations and bolstering of cultural worldviews. Journal of Experimental Social Psychology, 41, 91-113.

Van den Bos, K., \& Spruijt, N. (2002). Appropriateness of decisions as a moderator of the psychology of voice. European Journal of Social Psychology, 32, 57-72.

Van den Bos, K., \& Van Prooijen, J.-W. (2001). Referent cognitions theory: The role of closeness of reference points in the psychology of voice. Journal of Personality and Social Psychology, 81, 616-626.

Van Prooijen, J.-W., Van den Bos, K., \& Wilke, H. A. M. (2004). Group belongingness and procedural justice: Social inclusion and exclusion by peers affects the psychology of voice. Journal of Personality and Social Psychology, 87, 66-79.

Weary, G., \& Jacobson, J. A. (1997). Causal uncertainty beliefs and diagnostic information seeking. Journal of Personality and Social Psychology, 73, 839.

Weary, G., Jacobson, J. A., Edwards, J. A., \& Tobin, S. J. (2001). Chronic and temporarily activated causal uncertainty beliefs and stereotype usage. Journal of Personality and Social Psychology, 81, 206-219.

Weiss, H. M., Suckow, K., \& Cropanzano, R. (1999). Effects of justice conditions on discrete emotions. Journal of Applied Psychology, 84, 786-794.

Yavuz, H., \& Van den Bos, K. (2009). Effects of uncertainty and mortality salience on worldview defense reactions in Turkey. Social Justice Research, 22, 384-398. 